\title{
Use of An Applied Statistical Method to Optimize Efficiency of an Air Pollution Scrubber Within An Undergraduate Laboratory
}

\author{
Jimmy L. Smart \\ University of Kentucky
}

Keywords: EVOP, optimization, air pollution, scrubber.

Abstract. Optimal operation of a gas absorption column (scrubber) is based upon a favorable combination of operating conditions that will achieve the greatest reduction in contaminant removal at the lowest cost, while satisfying environmental regulations. Fine tuning and optimization of gas scrubbers are usually accomplished by operating personnel in the field once the equipment has been designed, constructed, and installed. Industrial supervisors do not encourage operating personnel to experiment with column operation by varying ranges of operating parameters. Inappropriate changes could cause upset conditions that might lead to release of contaminated gas streams and result in a violation of an approved environmental air permit.

A simple introduction to use of the Evolutionary Operation (EVOP) statistical method is provided to demonstrate how it can be applied to the optimization of an air pollution scrubber. This exercise was organized to be used in an undergraduate chemical engineering laboratory. The aim of this work is not to specifically identify the overall optimum set of operating conditions for maximizing scrubber performance, but to demonstrate use of the EVOP method. Students gain experience in use of the method and can apply learned principles to optimize operation of other engineering equipment. Final results of this study does identify favored packing material and in what direction the optimum will reside for conditions of temperature and scrubber liquor caustic concentration.

Introduction. Evolutionary Operation (EVOP) is a statistical method developed for incrementally moving a dynamic process in the direction of some optimum operational point. The EVOP method [1] was introduced in the late 1950's as a field application technique for improvement of existing industrial processes. In the University of Kentucky Chemical Engineering undergraduate laboratory, students operate a carbon dioxide scrubber to gain training in use of the EVOP method. Not only do students gain knowledge of how to design a scrubber, but they learn how the interplay of various operating parameters affect the overall scrubbing performance of the device. There are advanced statistical methods, such as strategies of experimentation [2], simplex optimization [3], response surface methodology [4], and advanced factorial design [5], but these methods are more complex and require much training for reliable application and interpretation. Most of these methods deal with strategy of experimentation when initially formulating a set of bench-scale experimental runs. The goal of the experimental design is to minimize the number of runs while maximizing the amount of useful information. On the other hand, EVOP was developed to be applied to an existing manufacturing process currently producing acceptable product. By exploring small incremental changes about the existing set of process conditions, the process can be improved and moved in the direction of some process optimum. EVOP is a simple technique that is relatively easy to apply and provides intuitive, yet statistically-based results.

A gas scrubber is a packed column that uses liquid media such as water to absorb and remove contaminants from polluted industrial gas streams. This scrubbing process often serves as a final process step prior to release of the "clean" air into the environment. Chemical engineering students in the undergraduate curriculum learn to design packed columns for use 
as air pollution control devices. Most curriculums include some hands-on training with these devices in a laboratory environment. These design techniques learned by students are approximate methods based upon such operating variables as column pressure drop, packing factors, and mass transfer coefficients. These approximations often serve as a fundamental basis for design and construction of air pollution control devices. However, in reality, final optimization and fine-tuning are often performed in the field by engineers upon already installed, operational equipment. The EVOP technique is ideally suited for optimizing existing equipment operation. In addition to EVOP, some investigators have applied other advanced statistical methods to the dynamic optimization of a packed gas absorber with success [6].

In this laboratory exercise, students are presented with a packed scrubber that is currently being used to remove $\mathrm{CO}_{2}$ from a simulated industrial stack gas. Gas flow rate, $\mathrm{CO}_{2}$ inlet concentration, and column diameter are fixed operational parameters. Existing conditions include use of once-through ambient water flowing countercurrent to gas flow in a column packed with spherical packing material. Students use principles of EVOP to optimize column performance by selecting appropriate column packing, liquid recirculation rate, caustic concentration, and temperature. Column performance in this exercise is defined as lowest $\mathrm{CO}_{2}$ emissions, not lowest cost.

After students become familiar with the equipment and have characterized existing scrubber performance, they are ready to apply the EVOP method. A $2^{3}$ factorial experimental matrix is set up to measure the response (level of $\mathrm{CO}_{2}$ emissions) from small changes in operating variables (liquid flow rate, caustic concentration, and temperature). Standard error limits are tabulated to build response surfaces to judge positive and negative effects of parameter changes for a given packing material. Results from these small changes are used to guide the students in making judgements as to what direction parameters should be adjusted to achieve a final process optimum.

The purpose of this laboratory exercise is to introduce students to the use and application of the EVOP method. Use of sodium hydroxide solutions to scrub $\mathrm{CO}_{2}$ emissions is not the most favored industrial method. Aqueous solutions of potassium hydroxide or amines, in conjunction with arsenite catalyst are usually more desirable from an economic standpoint [7]. However, sodium hydroxide solutions were selected for this exercise due to their ready availability in educational laboratories.

EVOP Method. Since the introduction of EVOP in the late 1950's, many books and journal articles have been published that discuss use of the method. This article is not intended as a survey review of EVOP. The reader is invited to consult the original publication [1] or other excellent discussions [8 - 11] for detailed information and applications of the method. The purpose of this article is to introduce undergraduate students in the chemical engineering laboratory curriculum to EVOP and provide a procedure and list of equipment for faculty who might wish to set-up a similar experiment at their location. EVOP is a statistically-based method that allows students to gain a fundamental understanding of interaction between independent and dependent process variables. This introduction provides a basis for further study leading to response surface theory and culminating in contemporary quality strategies in a manufacturing plant environment such as Total Quality Management [12] and Six Sigma [13].

In a research laboratory environment, strict requirements for formulating strategies of experiments can usually be satisfied. Usually, all independent and dependent variables can either be measured or carefully controlled. Principles behind orthogonal design, generation of response surfaces, randomization, experimental replication, and factorial designs can be successfully met. However, in a manufacturing plant environment, there are forces not subject to control by operating personnel, including economic factors, product demands, and other 
undefined influences. Quite often, orthogonal designs are not compatible with production requirements. EVOP is a procedure designed to meet the needed flexibilities inherent to the plant environment. It must be emphasized that EVOP is a routine method for permanent process operation, not an experimental procedure. It is to be applied in an existing plant operation, rather than used at the pilot/laboratory scale. It was developed to avoid undesirable characteristics of full-scale process experiments, requiring specially trained personnel and the subsequent production of off-specification product. EVOP requires no special staff and can be utilized by the usual plant operators after a brief training period.

Plant operators find EVOP to be appealing because of its instinctive approach. The philosophy behind the EVOP method is intuitive. It says to explore the effects of process variables near current operating conditions and make adjustments to drive the process in the direction that offers improvement, whether it be quality, reduced cost, greater output, or less waste. Another added bonus behind implementation of the EVOP method is that it improves overall understanding of the process itself. Plant personnel gain a firm understanding of the effects of process variables upon product quality. Also, subtle effects are often discovered that were never known to exist.

The basic idea behind use of EVOP is to improve the signal-to-noise ratio of an existing process in an effort to uncover relationships between operating variables. The signal is increased by deliberately introducing carefully chosen minor variations about an existing operational point, called the "works process". The noise level within a process is reduced by repetition of these minor changes and averaging the result. For example, suppose we are interested in optimizing the yield of an existing manufacturing process. The current operating procedure along with the specifications for operating variable setpoints is called the works process. Noise within the process arises from a variety of sources such as variability of raw materials, inability to precisely control process inputs, and from instrument and measurement error. The final variation in the product yield is a composite of all of these. The magnitude of this variation is measured by a statistical variable known as standard deviation. Often, effects upon the overall yield by changes in input variables (the signal) are buried in the noise of the process. Therefore, it is desirable to reduce the noise and increase the signal to discover what changes in input variables will lead to increased product yield (optimization).

The first step in implementing EVOP is to identify pertinent process variables associated with an existing process. Then, a cycle of process runs are designed around the normal or existing values of the process variables. Here, we are deliberately introducing small changes in the process signal or process outputs to investigate their effects. Differences between normal and proposed values are kept necessarily small to avoid the production of offspecification product. Generally, it is impractical to investigate the effects of more than three variables in an industrial process, so a $2^{3}$ factorial design is arranged. This design investigates the effects (response) of low and high levels of three process variables. Cycles of runs are repeated to replicate operational conditions and reduce experimental error. Here, we are reducing the noise level in the process by repeatedly measuring the process output at a fixed set of operating conditions.

Assume a $2^{3}$ factorial design is set up around our first phase (ambient temperature), where the variables to be studied are recirculation rate, caustic concentration, and packing material. A "phase" is defined as a defined set of variables to be tested and form the cubic geometry of the $2^{3}$ factorial design shown in Figure 1 . One complete "cycle" is defined as a complete collection of process runs from point $\hat{I}$ - Õ of the cube (phase). Anywhere from $3-6$ cycles are run for each phase to provide statistical analysis. The output response to be optimized is the $\% \mathrm{CO}_{2}$ concentration in the stack gas From Table 1, the experimental runs are set up to explore the low and high variations of these variables and the output responses for each set of conditions are noted at each apex of the cube shown in Figure 2. 
Once a factorial design is arranged, it is normal statistical practice to randomize the order of the runs within each cycle. Randomization ensures that if systematic trends occur from untested variables, these effects will not be mistaken for effects from deliberately introduced changes in tested variables. Randomization also validates our analysis which assumes that errors within cycles are independent of each other. In an actual plant manufacturing environment, it is difficult to organize a random run sequence. However, by following different run sequences over the course of various cycles, randomization is assured.

After four cycles are complete for phase one, the results are averaged for each variable effect (actual results shown in Table 1). The main effects and interaction between effects are determined from utilizing the averages shown from Figure 2.

Main effects are calculated as:

$$
\begin{array}{llll}
A & 1 / 4\left(\bar{y}_{2} \% \bar{y}_{4} \% \bar{y}_{6} \% \bar{y}_{8}\right)-1 / 4\left(\bar{y}_{1} \% \bar{y}_{3} \% \bar{y}_{5} \% \bar{y}_{7}\right) \\
\text { B ' } 1 / 4\left(\bar{y}_{3} \% \bar{y}_{4} \% \bar{y}_{7} \% \bar{y}_{8}\right)-1 / 4\left(\bar{y}_{1} \% \bar{y}_{2} \% \bar{y}_{5} \% \bar{y}_{6}\right) \\
\text { C' } 1 / 4\left(\bar{y}_{5} \% \bar{y}_{6} \% \bar{y}_{7} \% \bar{y}_{8}\right)-1 / 4\left(\bar{y}_{1} \% \bar{y}_{2} \% \bar{y}_{3} \% \bar{y}_{4}\right)
\end{array}
$$

Two-factor interactions are calculated as:

$A B^{\prime} 1 / 4\left(\bar{y}_{1} \% \bar{y}_{4} \% \bar{y}_{5} \% \bar{y}_{8}\right)-1 / 4\left(\bar{y}_{2} \% \bar{y}_{3} \% \bar{y}_{6} \% \bar{y}_{7}\right)$

AC ' $1 / 4\left(\bar{y}_{1} \% \bar{y}_{3} \% \bar{y}_{6} \% \bar{y}_{8}\right)-1 / 4\left(\bar{y}_{2} \% \bar{y}_{4} \% \bar{y}_{5} \% \bar{y}_{7}\right)$

$B C^{\prime} 1 / 4\left(\bar{y}_{1} \% \bar{y}_{2} \% \bar{y}_{7} \% \bar{y}_{8}\right)-1 / 4\left(\bar{y}_{3} \% \bar{y}_{4} \% \bar{y}_{5} \% \bar{y}_{6}\right)$

Three-factor interaction is calculated as:

$$
A B C^{\prime} 1 / 4\left(\bar{y}_{2} \% \bar{y}_{3} \% \bar{y}_{5} \% \bar{y}_{8}\right)-1 / 4\left(\bar{y}_{1} \% \bar{y}_{4} \% \bar{y}_{6} \% \bar{y}_{7}\right)
$$

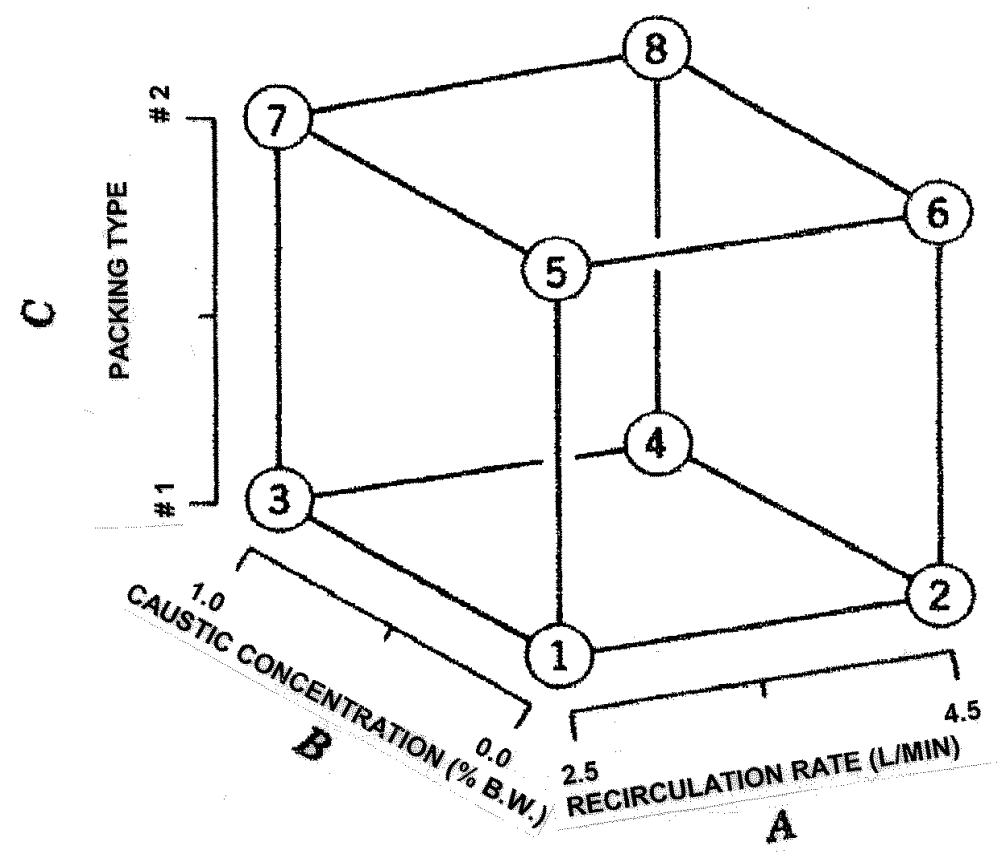

Figure 1. $2^{3}$ Factorial Design for Phase One 
Table 1. Eight Sets of Conditions of a $2^{3}$ Factorial Design (Phase 1 containing 4 cycles)

\begin{tabular}{|c|c|c|c|c|}
\hline Run & $\begin{array}{c}\text { A } \\
\text { recirculation rate, } \\
\text { L/min }\end{array}$ & $\begin{array}{c}\text { B } \\
\text { caustic concentration, } \\
\% \text { by wt }\end{array}$ & $\begin{array}{c}\text { C } \\
\text { packing type }\end{array}$ & $\begin{array}{l}\bar{y} \text {, average } \mathrm{CO}_{2} \\
\text { in stack gas, } \\
\% \text { by volume }\end{array}$ \\
\hline 1 & 2.5 & 0.0 & $\# 1$ & 9.87 \\
\hline 2 & 4.5 & 0.0 & $\# 1$ & 8.97 \\
\hline 3 & 2.5 & 1.0 & $\# 1$ & 7.45 \\
\hline 4 & 4.5 & 1.0 & $\# 1$ & 7.28 \\
\hline 5 & 2.5 & 0.0 & $\# 2$ & 9.90 \\
\hline 6 & 4.5 & 0.0 & $\# 2$ & 9.93 \\
\hline 7 & 2.5 & 1.0 & $\# 2$ & 6.10 \\
\hline 8 & 4.5 & 1.0 & $\# 2$ & 5.18 \\
\hline
\end{tabular}

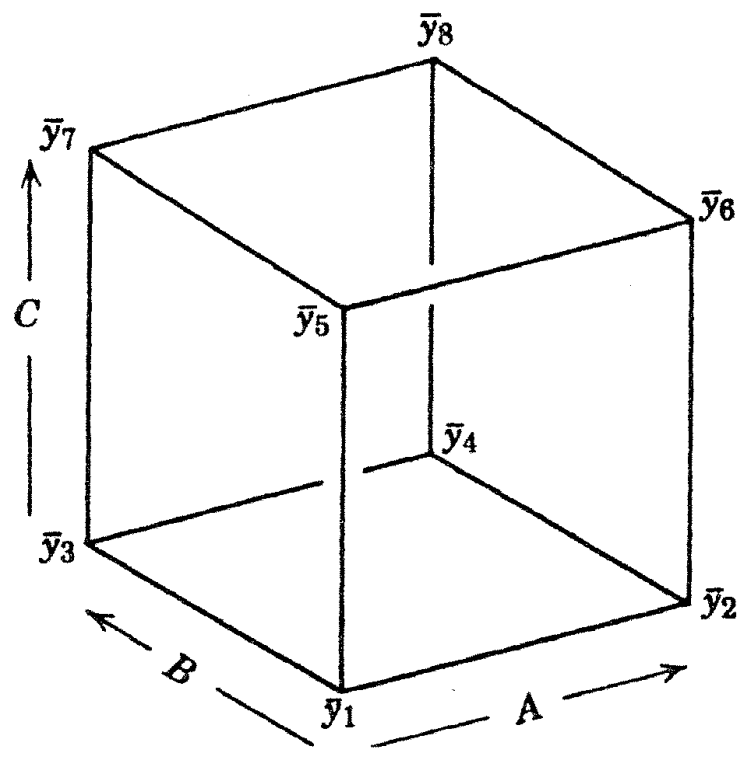

Figure 2. Average Output Responses for a $2^{3}$ Factorial Design. 
Results from these calculations are summarized in Table 2. A negative sign on the main effect or interaction is desirable in this exercise because it indicates a reduction in $\% \mathrm{CO}_{2}$ stack gas emissions.

Table 2. Analysis of Main Effects and Interactions

\begin{tabular}{|l|l|l|l|l|l|l|l|l|l|l|}
\multicolumn{1}{c|}{} & mean & $\begin{array}{l}\text { std } \\
\text { dev }\end{array}$ & $\begin{array}{c}\mathrm{A} \\
\text { recirc/ } \\
\text { temp }\end{array}$ & $\begin{array}{c}\mathrm{B} \\
\text { caustic }\end{array}$ & $\begin{array}{c}\mathrm{C} \\
\text { packing }\end{array}$ & $\mathrm{AB}$ & $\mathrm{AC}$ & $\mathrm{BC}$ & $\mathrm{ABC}$ & \pm 2 \\
phase I & 8.09 & 1.77 & -0.49 & -3.17 & -0.62 & -0.06 & 0.05 & -1.11 & -0.42 & \pm 1.25 \\
\hline phase 2 & 4.64 & 1.53 & -3.31 & -2.11 & 1.56 & -0.33 & -0.60 & -0.26 & -0.23 & \pm 1.08 \\
\hline
\end{tabular}

After main effects and interactions have been tabulated, we must use a statistical tool to help us decide what variable effect is significant, i.e., what response is above the "noise level" of the process. Traditionally, statisticians have used various tests, such as the student t-test, chisquared test, and F-test to analyze data for confidence intervals and analysis of variance. These tests are not appropriate in assessing the uncertainties associated with EVOP because of the small number of observations. Instead, the most practical way to evaluate EVOP uncertainty has been found to be use of 2 standard error limits. A standard error (S.E.) is the estimated standard deviation of the variable of interest. If the true standard deviation, $\sigma$, of the process variable was known, \pm 2 S.E. limits would represent approximately a $95 \%$ confidence limit. The true standard deviation is not known, but an estimate of the standard deviation, $\mathrm{s}$, can be calculated. We use this estimate to formulate our $\pm 2 \mathrm{~S}$.E. limits to guide us in interpreting what effects and interactions are significant. Variances and standard errors can be calculated from Table 3 [1]:

Table 3. Variances $\left(\sigma^{2}\right)$ and standard errors for main effects and interactions estimated from a $2^{p}$ factorial design after c cycles with estimate of the standard deviation, $\mathrm{s}$.

\begin{tabular}{|l|l|l|l|}
\hline Design & $2^{\mathrm{p}}$ & $2^{2}$ & $2^{3}$ \\
\hline Variance & $4 \sigma^{2} / \mathrm{c} 2^{\mathrm{p}}$ & $\sigma^{2} / \mathrm{c}$ & $\sigma^{2} / 2 \mathrm{c}$ \\
\hline Standard Error & $2 \mathrm{~s} /\left(\mathrm{c} 2^{\mathrm{p}}\right)^{1 / 2}$ & $\mathrm{~s} / \mathrm{c}^{1 / 2}$ & $\mathrm{~s} /(2 \mathrm{c})^{1 / 2}$ \\
\hline
\end{tabular}

An estimate of the true variance, $\sigma^{2}$, is calculated as

$$
s^{2} \cdot \frac{j_{i}^{n}\left(y_{i}-\bar{y}\right)^{2}}{n-1}
$$

where, $\mathrm{s}^{2}$ is an estimate of the true variance, $y_{\mathrm{i}}$ is an individual observation, $\bar{y}$ is the mean, and $\mathrm{n}$ is the total number of observations. An estimate of the true standard deviation is just $\sqrt{s^{2}}$.

For a $2^{3}$ factorial design, the standard error of effects is calculated as $s / \sqrt{2 c}$.

Therefore, the 2 S.E. limits for the effects in our design are provided by:

$$
\text { effect } \pm 2\left(\frac{s}{\sqrt{2 c}}\right)
$$


Final calculated results for standard error limits are shown in Table 2. Data collected from phase two of this exercise where temperature, caustic concentration, and packing material were evaluated, are shown in Table 4.

Please note in this laboratory exercise, in the interest of reducing student laboratory time to a reasonable period, the EVOP method has not been strictly followed in the following areas:

1) Larger ranges of temperature $\left( \pm 13^{\circ} \mathrm{C}\right)$ were selected to clearly demonstrate to students its effect upon scrubbing efficiency. In a plant environment, smaller temperature ranges $\left( \pm 5^{\circ} \mathrm{C}\right)$ would probably be selected for each factorial design (phase). Recall, one of the advantages of the EVOP method is the generation of minimal quantities of off-spec product.

2) In a plant environment, four cycles would typically be used to average the output response. Instead of cycling through all eight apexes of the factorial cube before beginning the second cycle, four distinct samples for each given set of experimental conditions were collected.

3 ) The run order was not strictly followed. For example, in phase one, in order to delay use of caustic, we followed the run order of 1-2-5-6-3-4-7-8.

Table 4. Eight Sets of Conditions of a $2^{3}$ Factorial Design (Phase 2 containing 4 cycles)

\begin{tabular}{|c|c|c|c|c|}
\hline Run & $\begin{array}{c}\mathrm{A} \\
\text { temperature, }\end{array}$ & $\begin{array}{c}\mathrm{B} \\
\text { caustic concentration, } \\
\% \text { by wt }\end{array}$ & $\begin{array}{c}\mathrm{C} \\
\text { packing type }\end{array}$ & $\begin{array}{c}\bar{y} \text {, average } \mathrm{CO}_{2} \\
\text { in stack gas, } \\
\% \text { by volume }\end{array}$ \\
\hline 1 & 12 & 1.0 & $\# 2$ & 5.05 \\
\hline 2 & 38 & 1.0 & $\# 2$ & 4.53 \\
\hline 3 & 12 & 2.0 & $\# 2$ & 3.30 \\
\hline 4 & 38 & 2.0 & $\# 2$ & 2.58 \\
\hline 5 & 12 & 1.0 & $\# 3$ & 7.25 \\
\hline 6 & 38 & 1.0 & $\# 3$ & 5.98 \\
\hline 7 & 12 & 2.0 & $\# 3$ & 5.43 \\
\hline 8 & 38 & 2.0 & $\# 3$ & 3.05 \\
\hline
\end{tabular}

Experimental Set-up. An existing experimental laboratory scrubber package by Armfield, Ltd. (see Figure 3) was modified for this exercise. The overall column is made of clear plastic with dimensions of $9 \mathrm{~cm}$ OD by $1.7 \mathrm{~m}$ tall. The overall column consists of two packed sections, each having a packed bed depth of $55 \mathrm{~cm}$ and one liquid redistributor. Three types of packing are offered to students for optimization purposes. These are $1 / 2 " 1.3 \mathrm{~cm})$ diameter polypropylene balls, 3/8" $(1 \mathrm{~cm})$ glass pall rings, and 3/16" $(0.5 \mathrm{~cm})$ Jaeger stainless steel slotted rings (see Figure 4 and Table 5). During operation of the scrubber, $\mathrm{CO}_{2}$ is supplied from a standard gas cylinder, regulated through a rotameter, and mixed with air from an air blower to provide a $10 \%$ by volume mixture of $\mathrm{CO}_{2}$ in air (compare this to $\mathrm{CO}_{2}$ emissions from coal-fired power plants that are typically $14 \%$ ). This gas mixture is routed to the bottom of the packed column and allowed to flow upward through the column. Scrubber liquor enters the top of the column and flows downward through the packed bed where it acts to absorb (scrub) $\mathrm{CO}_{2}$ from the gas stream. "Clean" gas exits through the top of the scrubber. The purpose of this exercise is to find the combination of operating parameters to minimize the $\%$ $\mathrm{CO}_{2}$ leaving the scrubber stack. 


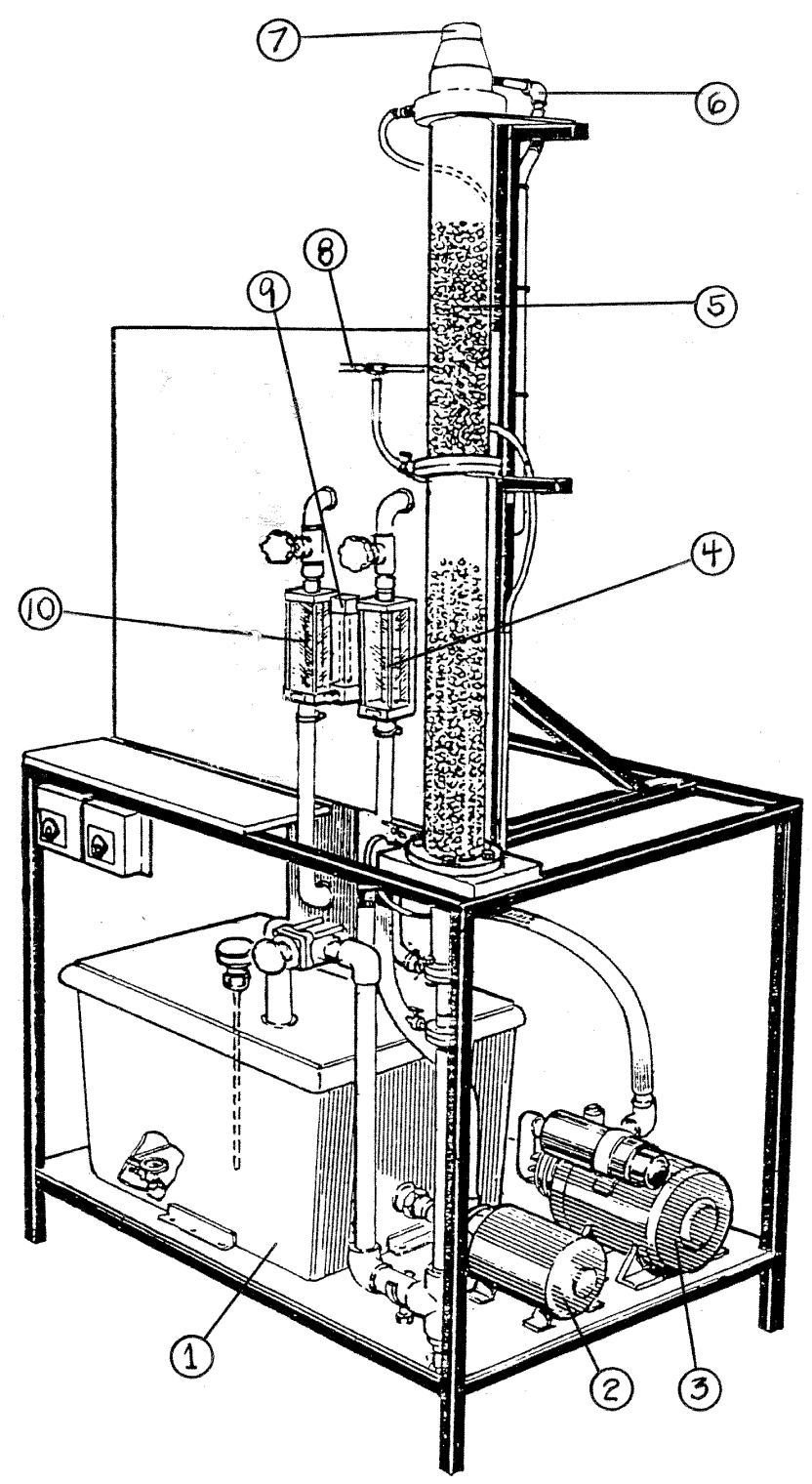

Figure 3. Gas Absorption Column

1. Recirculation sump ( $40 \mathrm{~L}$ capacity)

2. Liquid recirculation pump

3. Air blower

4. Rotameter for recirculated liquid (1 - $10 \mathrm{~L} / \mathrm{min})$

5. Packing material (clear plastic column)

6. Scrubber liquor inlet

7. Scrubber discharge stack (gas outlet)

8. Pressure taps for checking $\Delta p$ across the packed column

9. Rotameter for $\mathrm{CO}_{2}(0-20 \mathrm{~L} / \mathrm{min})$

10. Rotameter for air (20 - $180 \mathrm{~L} / \mathrm{min})$ 
An inexpensive $(\$ 350)$ Bacharach Fyrite ${ }^{\circledR}$ gas analyzer was used to measure $\mathrm{CO}_{2}$ concentrations in air for both scrubber inlet and exit. Other more expensive gas analyzers and analytical equipment provide greater accuracy, but $\pm 0.1 \mathrm{vol} \%$ was adequate for purposes of this exercise. Precision, or repeatability, under experimental conditions proved to be $\pm 8 \%$. The Fyrite provides a very quick and easy method for measurement of $\mathrm{CO}_{2}$ in air. It employs the Orsat method of volumetric analysis involving chemical absorption of carbon dioxide into a potassium hydroxide solution. A rubber bulb is used to draw the gas sample into the indicator solution. The instrument is inverted and the percentage of gas absorbed by the Fyrite fluid is immediately read from the scale $(0-20 \%)$.

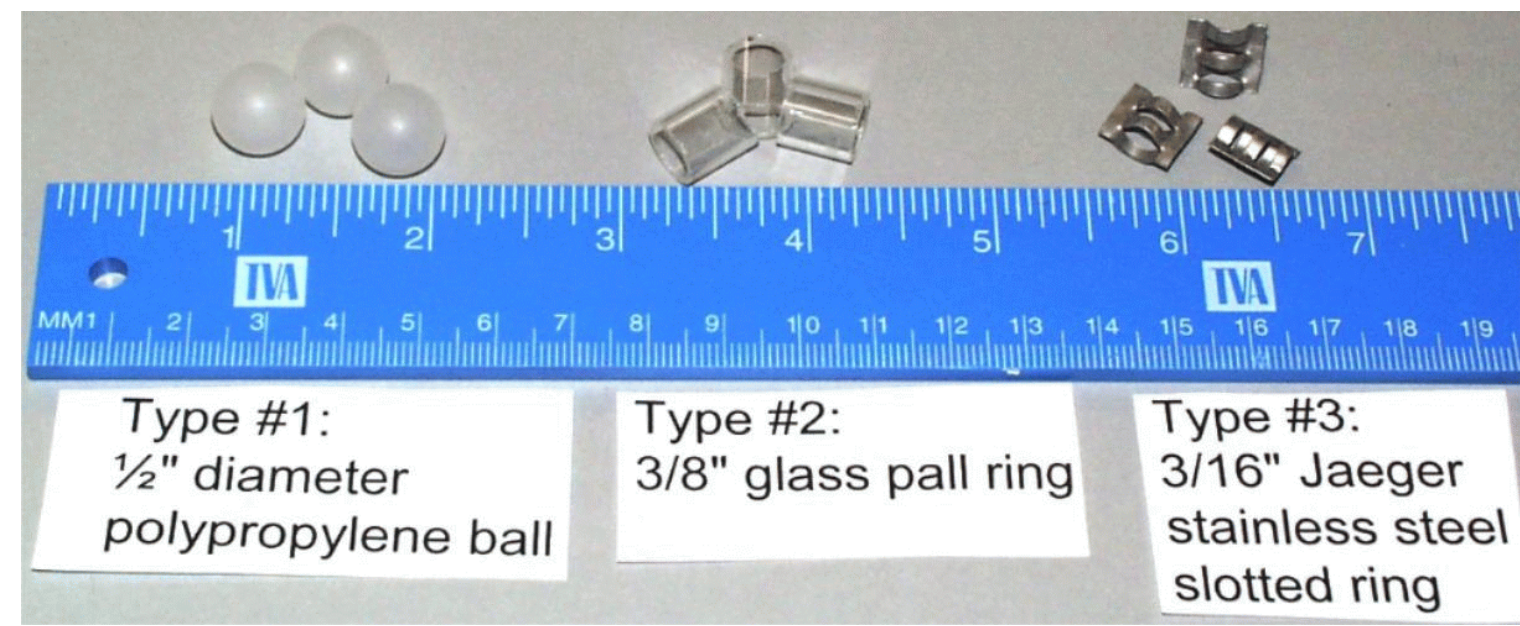

Figure 4. Random Packing Used for Scrubber Internals.

Table 5. Properties of Random Packing

\begin{tabular}{|l|c|c|c|}
\hline \multicolumn{1}{|c|}{ Packing type } & $\begin{array}{l}\text { Packing } \\
\text { pieces/cm }\end{array}$ & $\begin{array}{l}\text { Surface } \\
\text { area/volume } \\
\left(\mathrm{cm}^{2} / \mathrm{cm}^{3}\right)\end{array}$ & $\begin{array}{l}\text { Pressure drop: } \\
\Delta \mathrm{p} / \mathrm{L} \text { (cm water/cm }) \\
\text { @ 2.5 ml liquid/min }\end{array}$ \\
\hline $\begin{array}{l}\text { \#1: 1/2" diameter } \\
\text { P/P sphere }\end{array}$ & 4.2 & 21.3 & 0.16 \\
\hline $\begin{array}{l}\text { \#2: 3/8" glass pall } \\
\text { ring }\end{array}$ & 5.5 & 35.2 & 0.06 \\
\hline $\begin{array}{l}\text { \#3: 3/16" Jaeger } \\
\text { s.s. slotted ring }\end{array}$ & 18.1 & 49.0 & 0.05 \\
\hline
\end{tabular}

Temperature of the scrubber recirculation sump was controlled by a bath circulator (NESLAB Instruments, RTE-100) fitted with an external cooling coil.

For data collection in an undergraduate laboratory exercise, the first set of data can be collected in one afternoon, but the elevated and reduced temperature settings will require completion on subsequent days. 
Discussion. In actual scrubbers at industrial power plants, $\mathrm{Ca}(\mathrm{OH})_{2}$, called slaked lime, is used to remove the hazardous air pollutant, sulfur dioxide, from stack gases. In this experiment, another strong base, $\mathrm{NaOH}$, will be used to remove $\mathrm{CO}_{2}$ from our simulated stack gas. The primary reactions that occur during the scrubbing process are:

$$
\begin{aligned}
& \mathrm{CO}_{2}(\mathrm{~g})+\mathrm{H}_{2} \mathrm{O}\left(\mathrm{R} \cong \mathrm{H}_{2} \mathrm{CO}_{3}(\mathrm{R}\right.
\end{aligned}
$$

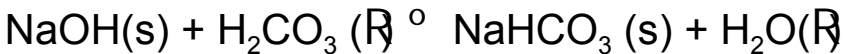

$$
\begin{aligned}
& 2 \mathrm{NaOH}(\mathrm{s})+\mathrm{H}_{2} \mathrm{CO}_{3} \text { (R } \cong \mathrm{Na}_{2} \mathrm{CO}_{3} \text { (s) }+2 \mathrm{H}_{2} \mathrm{O} \text { (R) }
\end{aligned}
$$

In equa. (1) a weak dibasic acid, carbonic acid, is formed when carbon dioxide is mixed with water. As the caustic solution (a strong base) contacts the carbonic acid, either sodium bicarbonate is formed from equa. (2) or sodium carbonate from equa. (3). The reactions can be found as titration curves in any standard analytical chemistry text [14] and can be monitored in the scrubber with a $\mathrm{pH}$ probe.

In the absorption process, the overall rate is governed by diffusion and chemical reactions occurring in the liquid phase. The reaction is a pseudo first-order reaction between dissolved $\mathrm{CO}_{2}$ and $\mathrm{OH}^{-}$in the liquid, and is of the same order of magnitude as the rate of diffusion [15].

For an industrial scrubber, a tank supplying scrubber medium typically contains several thousand gallons. Unfortunately, the working volume of the small recirculation sump in our experimental apparatus is only about $38 \mathrm{~L}$. Based upon an assumption of plug flow at a recirculation rate of $4.5 \mathrm{~L} / \mathrm{min}$, where the pump suction and recirculated liquor return are located at opposite ends of the sump, a working time of only 8.5 minutes is available. The unsteady state nature of the scrubbing action is charted in Figure 5. Sure enough, for about 8 minutes, the $\% \mathrm{CO}_{2}$ by volume in air is 5.0 . After this period, the $\% \mathrm{CO}_{2}$ slowly climbs to a steady state value of 8.8 after 44 minutes. During the initial 8 minutes, the sodium carbonate salt (equa. 3 ) is probably being formed. After this initial period, there are probably equilibrium competitions between equations (2) and (3), until a steady state condition is attained.

As previously mentioned, repeatability of experimental measurements with the gas analyzer was $\pm 8 \%$. This value would be viewed as high in a laboratory setting, but is probably a realistic value in a plant environment. The lack of repeatability was not due to the instrument itself, but rather due primarily to fluctuations in the gas rotameter settings, low temperature effects at the $\mathrm{CO}_{2}$ cylinder regulator, and irregular mixing in the column packing.

Results. The main effects and interactions between process variables are summarized in Table 2. In phase 1 , recirculation rate (A), \% caustic (B), and packing material (C) were evaluated. From consideration of each effect \pm 2 S.E., it appears the increase of caustic from $0 \%$ to $1 \%$ had a strong negative effect (decreasing the $\% \mathrm{CO}_{2}$ in the stack gas, which is desired). The other effects are not significant since they are below the error limits and can be considered to be within the noise of the process. One surprising result is the fact that the main effect $(A)$ of recirculation rate was not significant. There was no advantage to increasing the recirculation rate from 2.5 to $4.5 \mathrm{~L} / \mathrm{min}$. Evidently, the scrubbing effect is not diffusion rate limited, but reaction rate limited.

In phase 2 of Table 2 , temperature (A), \% caustic (B), and packing material $(C)$ were evaluated. From consideration of each effect \pm 2 S.E., it appears only the main effects of temperature $(A), \%$ caustic $(B)$, packing material $(C)$ were significant. The result of increasing the temperature and \% caustic had a strong negative effect (decreasing the $\% \mathrm{CO}_{2}$ in the stack gas). On the other hand, switching the packing from pall rings to more open stainless steel slotted rings had a strong positive effect (increasing the $\% \mathrm{CO}_{2}$ in the stack gas). This is a somewhat surprising result, since the slotted rings offer more surface area/volume 


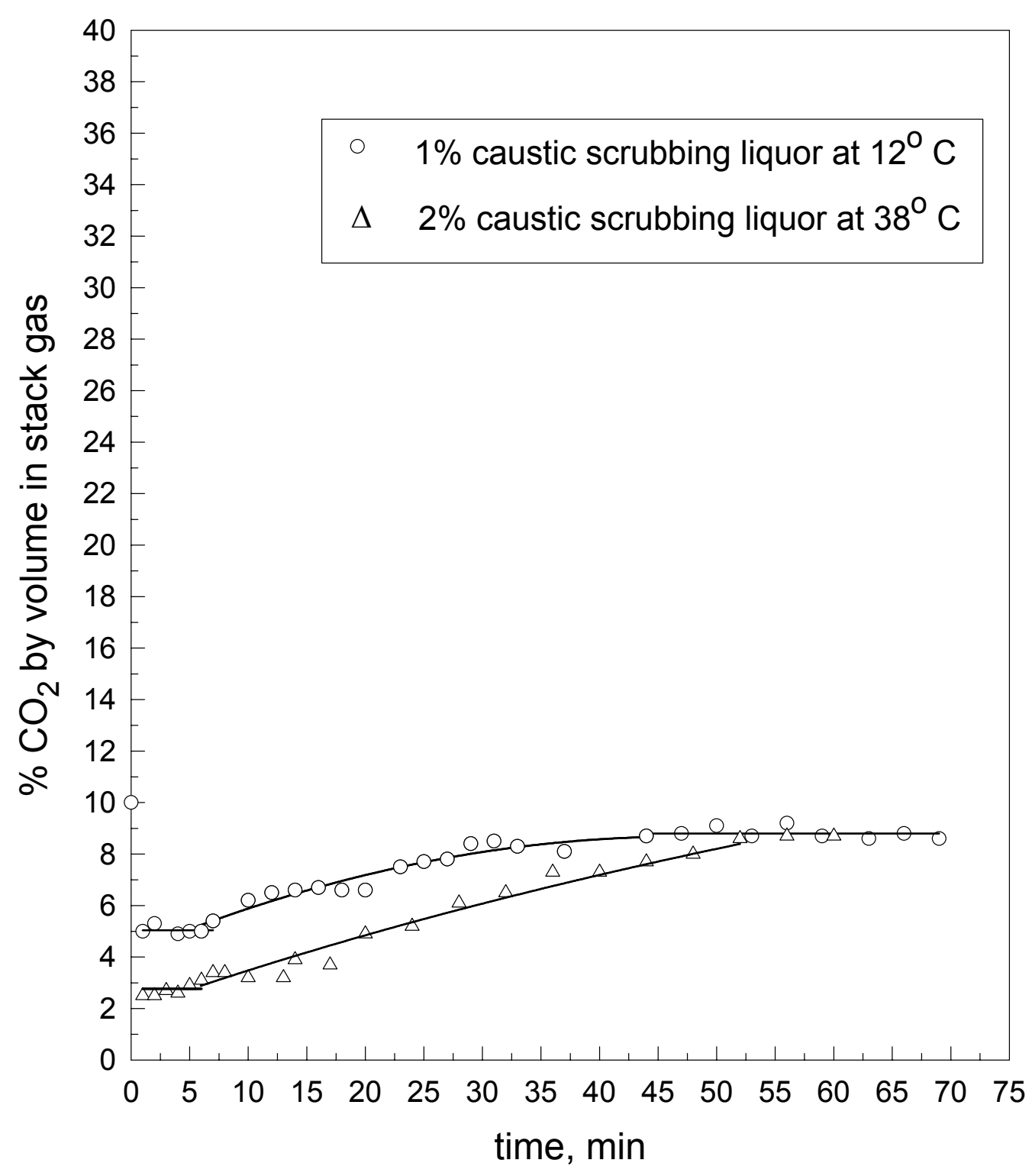

Figure 5. Unsteady State Nature of Scrubber Performance: recirc rate: $4.5 \mathrm{~L} / \mathrm{min}$, \#2 packing (lines added to guide the eye.)

and less pressure drop (see Table 5). This can be explained as it was shown from results of phase 1 that the scrubbing effect is limited by reaction rate, not diffusion rate. The slotted rings offer a more open geometry (less $\Delta p$ ) and therefore less liquid holdup within the packed beds. With glass pall rings, there is more liquid holdup within the column that favors reaction between $\mathrm{CO}_{2}$ to form the carbonates. In the case of packing \#1 (P/P spheres), this geometry offers a much reduced surface area/volume which lowers the reaction rate between the gas and liquid phases within the column.

Conclusions. From this abbreviated application of EVOP, we can draw some conclusions as to what direction the optimum for this scrubbing process may lie. The optimum will reside in a 
direction of elevated operating temperature and higher \% caustic in the scrubbing liquor. Packing material \# 2 (pall rings) is more desirable in decreasing the overall $\% \mathrm{CO}_{2}$ in the stack gas, but is just slightly out of the error limits. In the final analysis, packing \# 3 (slotted rings) may be a more favorable choice because of the lower operating cost (less $\Delta \mathrm{p} /$ length of packing height).

From the EVOP analysis, use of higher \% caustic reduced $\mathrm{CO}_{2}$ emissions from our scrubber stack. Where might the overall process optimum reside? From the Material Safety Data Sheet (MSDS), sodium bicarbonate is soluble in water to about $8 \%$ b.w. at $18^{\circ} \mathrm{C}$. Therefore, this condition would be the limiting factor on what maximum concentration of $\mathrm{NaOH}$ to use in the scrubbing liquor. Anything above about $8-10 \%$ would cause salting-out of solids that would foul and possibly occlude scrubber packing. It is interesting to compare the main effect of $\%$ caustic for phase 1 and phase 2 . Moving from $0 \%$ caustic to $1 \%$ had a very strong negative effect $\left(\mathrm{CO}_{2}\right.$ reduced in stack gas), whereas moving from $1 \%$ to $\%$ had a less strong negative effect. The response surface is not linear. This situation calls for additional investigation as a process optimum may reside somewhere between $2 \%$ caustic and the recommended maximum limit of $10 \%$ caustic. Other investigators [16] have found the optimum mass transfer coefficient to reside at a $2 \mathrm{M} \mathrm{NaOH}$ solution (about $8 \%$ b.w.).

Where might the elevated process optimum temperature lie? A cost analysis would have to be performed on a better defined response surface to closely define this optimum. In a plant environment, unless low pressure waste steam is available, the energy costs to heat the scrubber liquor is probably not justified. However, one point to consider is that usually inlet stack gases fed to scrubbers, especially those from power plants, are often at elevated temperatures. Another alternative is to add $50 \%$ b.w. caustic with enough water in a mixing tee to form a $10 \%$ b.w. caustic solution just prior to its introduction to the scrubber. This method would allow some elevation of temperature due to heat of solution.

This exercise has been prepared to give the undergraduate student experience in the use and application of the EVOP method in a laboratory environment. As demonstrated, the student could set up additional variable ranges to be tested for phase 3,4 , and so forth to perform a final optimization of the overall scrubbing process.

\section{References}

1. Box, G., and N.R. Draper, Evolutionary Operation, John Wiley \& Sons, NY, 1969.

2. Box, G.E.P., Hunter, W.G., and J.S. Hunter, Statistics for Experimenters, John Wiley \& Sons, NY, 1978.

3. Walters, F.H., Morgan, S.L., Parker, L.R., and Deming, S.N., Sequential Simplex Optimization, CRC Press, Boca Raton, 1991.

4. Montgomery, D.C., Design and Analysis of Experiments, John Wiley \& Sons, NY 2001.

5. Box, G., Hunter, W.G., and Hunter, J.S., Statistics for Experimenters, John Wiley \& Sons, NY, 1978.

6. Hoerner, G.M., and W.E. Shiesser, Simultaneous Optimization and Transient Response Evaluation of Packed-Tower Gas Absorption, Chem. Engr. Prog. Symp. Ser., 61(55), 1965, pp. $115-125$.

7. Danckwerts, P.V., and M.M. Sharma, The Absorption of Carbon Dioxide Into Solutions of Alkalis and Amines, The Chem. Engr., Oct 1966, pp. 244 - 280.

8. Klingel, A.R., and R.G. McIntyre, An Experimental Strategy for Investigating Commercial Processes, Applied Statistics, Vol 11(2), June 1962, pp. 79 - 92.

9. Spendley, W., Hext, G.R., and Himsworth, F.R., Sequential Application of Simplex Designs in Optimisation and Evolutionary Operation, Technometrics, Vol 4(4), Nov 1962, pp. 441 - 461. 10. Carpenter, B.H., and H.C. Sweeny, Process Improvement with Simplex Self-Directing Evolutionary Operation, Chem. Engr., (July5, 1965), pp. 117 - 126. 
11. Scarrah, W.P., Improve Production Efficiency Via Evolutionary Operation, Chem. Engr., (Dec 7, 1987), pp. 131 - 133.

12. Schmidt, S.R., Kiemele, M.J., and Berdine, R.J., Knowledge Based Management, Air Academy Press, Colorado Springs, CO, 1997.

13. Breyfogle, F.W., Implementing Six Sigma: Smarter Solutions Using Statistical Methods, John Wiley \& Sons, NY, 1999.

14. Fritz, J.S., and G.H. Schenk, Quantitative Analytical Chemistry, $4^{\text {th }}$ Ed., Allyn \& Bacon, Boston, 1979, p. 184.

15. Sherwood, T.K., and R.L. Pigford, Absorption and Extraction, McGraw-Hill, NY, (1952), p. $358-363$.

16. Tepe, J.B., and B.F. Dodge, Trans. Am. Inst. Chem. Engrs., 39, (1943). 